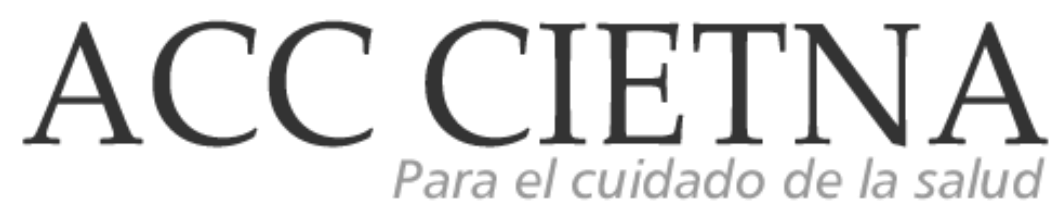

https://doi.org/ $10.35383 /$ cietna.v6i2.267

\title{
Basics of Health Care Team Relationships and Interprofessional Practice*
}

\author{
Koloroutis Mary ${ }^{1}$
}

\section{INFORMACIÓN DEL ARTÍCULO ABSTRACT}

\section{Historia del artículo:}

Recibido el 15 de noviembre 2019

Aceptada el 29 de noviembre 2019

\section{Keywords:}

Relationships

Health Care Team

Interprofessional Practice

Relationship-based care is a philosophy, an operational plan for excellence and a way of being.

It is essential that the transformation of a health care organization be a team effort based on a common vision, values and anticipated results.

\section{Conceptos básicos de las relaciones del equipo de atención} de salud y la práctica interprofesional

\section{RESUMEN}

\section{Palabras clave:}

Relaciones

Equipo de atención de salud

Práctica interprofesional

El cuidado basado en las relaciones es una filosofía, un plan operativo para la excelencia y una forma de ser.

Es esencial que la transformación de una organización de atención médica sea un esfuerzo de equipo basado en una visión, valores y resultados anticipados comunes.

\section{Introducción}

American Surgeon and writer Atul Guwande spoke an important truth when he said, I think the extreme complexity of medicine has become more than an individual clinician can handle. But not more than teams of clinicians can handle.
In this presentation I will discuss the value, importance and basics of high-quality teamwork and interprofessional practice - essential for quality, for safety, and for building the kind of health care community that serves not only the patient, but the clinicians as well. A sense of belonging to a team of people committed to a

IRN, CEO Creative Health Care Management, Urbana-Champaign, IL, UNITED STATES. Email: chcm@chcm.com

*Conferencia impartida en el I Congreso Internacional de Enfermería y XII Jornada Internacional de Investigación en Ciencias de Enfermería el 4, 5, 6 diciembre del 2019 
higher purpose - and infinite good is a source of energy and inspiration for all involved.

In 1977, two Boeing jets collided on the Spanish island of Tenerife, killing583 passengers. It was the deadliest accident in aviation history. Less than a year later, United Flight 173 crashed into suburban Portland, killing two crew members and eight passengers. The National Transportation Safety Board found that many factors contributed to these crashes, including a problem found in other crash investigations: Teams did not communicate well. Not only did the air traffic control team and cockpit crews misinterpret each other, but also, in the Portland crash, within the cockpit, the captain disregarded input from junior crewmembers, and junior crew members lacked the assertiveness/courage to speak up.

Two years after these tragic crashes, the National Aeronautics and Space Administration (NASA) sponsored a conference highlighting its research of aviation accidents. The research pointed to the importance of human factors, including failures in communications, decision making, and leadership. In other words, suboptimal team functioning and cockpit culture contributed to significant loss of life (Helmreich, Merritt, \& Wilhelm, 1999). Because of the National Transportation and Safety Boards investigations and NASA research, game-changing safety procedures and protocols were enacted. Like aviation, health care is a life-and-death endeavor that has struggled with preventable errors.

In 2000, the Institute of Medicine (IOM) released a landmark report: To Err is Human: Building a Safer Health System, which estimated that between 44,000 and 98,000 people die in hospitals each year due to preventable medical errors (Kohn et al., 2000). What aviation and health care safety research reveals is that breakdowns in communication, not bad people or institutions (though institutional factors can contribute to bad communication), lead to lapses in safety.

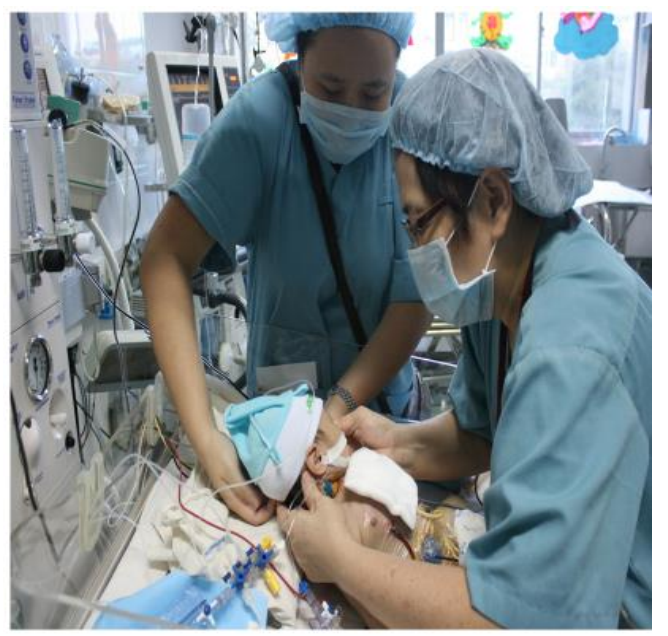

Kita, 2010; Makary, 2016; Moorthy,Munz, Adams, Pandey, \& Darzi, 2005; Shanafelt, 2009; Yule, Flin,Paterson-Brown, Maran, \& Rowley, 2006

Although patient harm from medical error does occur due to poor technical skill, lack of relational, not technical proficiency, is at the center of most medical errors and injuries.

It is sometimes hard to comprehend that relational skills override technical ability when it comes to overall team performance, but the evidence tells a powerful story. Notably, studies by researchers at the Massachusetts Institute of Technology, Carnegie Mellon University, Harvard University, and elsewhere tell us what successful teams across all industries have in common.

Most high-performing teams have two key ingredients

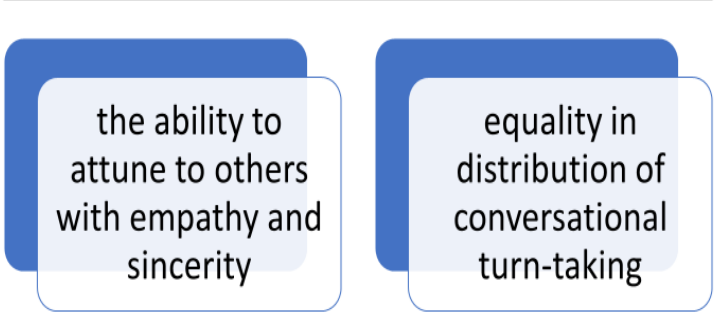

Goleman \& Boyatzis, 2008; Koloroutis \& Trout, 2012 
Most high-performing teams have two key ingredients. First, they have relational competencies, characterized by the ability to attune to others with empathy and sincerity.

Reliably successful teams can detect social cues, such as when someone is feeling upset or left out and respond to them with curiosity and interest. On the other hand, people on ineffective teams are unable to do this with consistency and demonstrate far less sensitivity toward teammates (Woolley, Chabris, Pentland, Hashmi, \& Malone, 2010).

Second, in reliably successful teams, team members speak roughly the same amount-what social science researchers refer to as the equality in distribution of conversational turn-taking.

Remarkably, if only one person or a small group speaks all the time, the collective intelligence of the team diminishes (Woolley, et al. 2010). These two important yet almost imperceptible practices create the conditions for psychological safety, respect, and open and honest communication (Duhigg, 2016; Edmundson, 2012; Goleman, 1998; Goleman \& Boyatzis, 2008; Lieberman, 2013; Siegel, 2007). Indeed, these relational proficiencies (attune and conversation turn taking) are essential to achieving the best possible outcomes for patients and their loved ones.

In health care, relational competence is often an organizational blind spot. (It is assumed people know how to establish healthy relationships - or that it comes naturally - or that some people are good clinicians, but poor at relationships and somehow, we simply need to accept that.) what we know from safety and quality research is that it is every bit as important to continuously improve relational skills within teams as it is the structures and processes that undergird them. The commitment to developing teams, then, takes a very special kind of relationship-based organization.
Because teams are systems, they thrive or fail based on the quality of the interplay of the people, processes, and structures that comprise them. While we know that the processes and structures of teams are important (which is why there are countless books on those topics alone), I am limiting the scope of this presentation to the personal and interpersonal dimensions-the people component of teams. When teams are built around adequate processes and structures, it is the ability of team members to relate competently to the patient and family, as well as to one another, that becomes the make-or-break condition for quality, safety, and a good patient experience.

In research conducted by Press Ganey in 2014, over 6.6 million patients responded to survey items regarding their patient experience. The number one factor that correlated with "likely to Recommend the Hospital" (at 84\%) was "staff worked together to care for you." The other top ones were: Explanations provided during treatment; staff included patient in treatment decisions, and how well pain was controlled.

Intentional collaboration and teamwork is a fundamental requirement for patients to feel held and safe in our care. And, clearly involving the patient as a key part of the team is as important as the way the team functions overall.

The People Component of Teams = "Teaming" Good care happens when teams perform health care processes with reliability. People suffer unnecessarily and even die when teams don't perform these processes well. Healing occurs when teams-and not just the individuals on teams, but the teams themselves-hold patients and families in the center.

This holding is complicated, of course, by the fact that teams continuously shape-shift based on need and circumstance. Further, the highly variable circumstances of illness create ambiguity 
about what is going on with a patient and uncertainty about the best course of action, which must be based partly on the values and preferences of patients. Teams are challenged by these two questions: How do we assure reliable care and compassionate holding in the face of necessarily complex processes and shape-shifting teams? And how do we foster adaptability in the face of the ambiguity, uncertainty, and rapidly changing circumstances of illness?

Amy Edmondson of the Harvard Business School, in her book Teaming: How Organizations Learn, Innovate, and compete in the Knowledge Economy, defines teaming: Teaming is a verb. It is a dynamic activity, not a bounded, static entity. It is largely determined by the mindset and practices of teamwork, not by the design and structures of effective teams. Teaming is teamwork on the fly. It involves coordinating and collaborating without the benefit of stable team structures, because many operations, such as hospitals, power plants, and military installations, require a level of staffing flexibility that makes stable team composition rare. In a growing number of organizations, the constantly shifting nature of work means that many teams disband almost as soon as they've formed. You could be working on one team right now, but in a few days, or even a few minutes, you may be on another team. (Edmondson, 2012, p. 14)

In other words, the interpersonal aspect of teams requires defining team and teaming as verbs. We have seen that productive, efficient, compassionate teaming happens when people become proficient at these four relational practices: attuning, wondering, following, and holding.

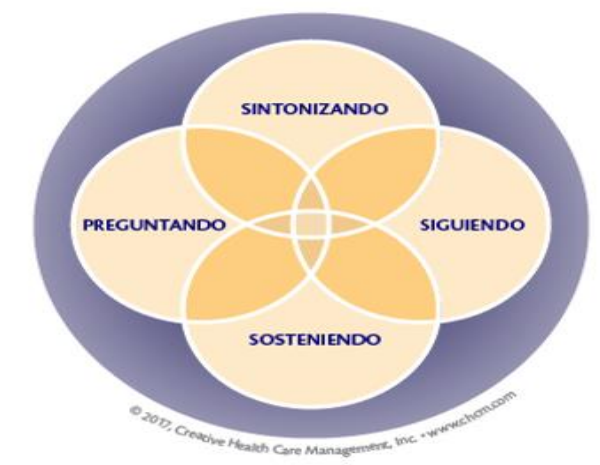

Koloroutis, M. and Trout, M. (2012) Verme como una persona.

Applying Attuning, Wondering, Following, and Holding for Effective Teaming

My co-author and psychologist Michael Trout and I defined attuning, wondering, following, and holding as four mindful therapeutic practices that result in connecting in the moment with patients and families. We discovered in our work with clinicians and health leaders that these four practices facilitate connection in all relationships personal and professional. On Friday, I will go deeper into the importance and impact of these practices applied to patients and families - today, I will introduce these four practices as a mindful framework for effective team connection. As you think with me about these practices, please hold in your mind the two ingredients identified in team research that predict high performing teams:

1. Attuning to each other with empathy and sincerity

2. Equality and Distribution in Conversation Turn taking.

I think you will be able to see how intentional application of these four practices support high team functioning and the ingredients of attuned empathy and conversation turn taking.

We will examine the application of each practice in turn.

Attuning: Attunement arises from our brain's natural capacity to relate with others. When we attune with compassion, we are harnessing our 
innate human inclination for meaningful connection. Nearly all people share this remarkable capacity and yearn for human connection.

Attunement is vital because it creates a felt sense of connection. Without it, team members feel disjointed and communication is less coherent; under these conditions, meaning and purpose are often lost. Remarkably, many teams function in a disjointed, disorganized way simply because they are unaware of just how pivotal attunement is to team communication and team efficacy.

Compassionate attuning is the interpersonal process that enables people to have meaningful interactions and to feel moved to acton another's behalf. It is, therefore, essential to healthy teams.

Example of Interprofessional Teaming with Stellar Results:

At Children's National Health System in Washington, D.C., the clinical team regularly cares for kids who are in crisis. In fact, the term children with medical complexity (CMC) is all too familiar. That term was used to describe Leah an eightyear-old patient. She has severe autism; some of her symptoms include becoming highly distressed by unfamiliar people and stimuli, and she has difficulty communicating. Her parents are deeply knowledgeable about her needs and ways to care for her.

They just don't happen to have a formal clinical title, as the other members of her care team do. For example, there is a neurologist, gastroenterologist, and an anesthesiologist, but the team at Children's knew Leah's parents as Leahologists. Experts in understanding and caring for their child.

So, when Leah was diagnosed with Crohn's disease, the interprofessional team ensured that there were representatives on the team who touched all aspects of Leah's care, including her parents.

Fortunately, Leah and her family had the benefit of a highly technically skilled team who compassionately tuned in to her unique needs while also tuning in to how different members of the team might be able to meet those needs. The whole team-Leah's parents includedconsidered the best way to provide a regimen of infusions, usually given in an outpatient clinic. Even though this was a terrifying option because of Leah's reactivity to the unfamiliar, the team compassionately moved forward with treatment. They customized care as best they could, but despite their efforts, treatment proved traumatic.

Because of the cohesive, highly attuned relationship the team created with one another, Leah's parents spoke up right away, and there was honest dialogue about other options. Undeterred and on a mission to help Leah, the team tried inpatient infusions. Even with a more specialized approach, this too was traumatic and overwhelming. The team paused to attune to one another again and ultimately came up with a novel plan: infusions, along with non-operating room anesthesia (NORA). Along the way, the care team invited people from multiple specialty groups onto the team to provide care unrelated to Crohn's but that would also require sedation, such as dental and skin care. Leah's mother performed routine personal hygiene including facial, nail, and ear care while Leah was under anesthesia, and her father was permitted to gown up and hold her hand as she was going under and coming out of anesthesia. In another accommodation, a nurse and anesthesiologist met the family in a parking garage and worked with the security department to clear halls and 
elevators to travel to the NORA room, thus limiting environmental stressors and triggers.

To be sure, in Leah's care, people spoke up, took all perspectives into account and weren't afraid to try new approaches. The team's ability to attune to one another, listen to what mattered most to the family, and adjust with each new episode of care revealed the team's relational competence, as well as their commitment to the best possible technical care. The team's attune collaboration led to innovative interventions and significantly reduced avoidable suffering and post traumatic memories for Leah, her parents, and the staff.

The real power of teamwork lies in the way people come together and tune in to one another to fulfill a shared purpose. Teams everywhere, LIKE those at Children's National, have the potential to be catalysts of hope and healing for patients in crisis.

Wondering is the practice of being genuinely interested in team members including what each person can contribute. It requires an openhearted curiosity about what can be learned from each individual.

The term wondering might seem distinctly nonclinical, but when we bring a mindset of wondering to teamwork, especially in patient care, it is a profoundly effective clinical tool. Take, for example, the experience of a team member raising a concern about a patient in a busy clinic or emergency department. We may initially be annoyed, thinking, "I don't have time for this," but the decision to wonder, as opposed to quickly judging the suggestion to be insignificant, can mean the difference between life and death.

As team members, wondering can also mean pausing to consider whether we have all the needed voices on the team.

Reflection on Occupational Therapy as a Member of the Team:
Louise was 75 years old and had multiple medical conditions; her health history included two heart attacks and breast cancer, and she was currently dealing with leukemia, dizzy spells, heart failure, macular degeneration, and anxiety. She was hospitalized 58 times in one year with complaints seemingly related to any and all of these conditions; no known etiology was found for her symptoms. When Dora, a home health aide, visited Louise to assist her with bathing after a recent hospitalization, she was surprised to find her at the sink doing dishes with her adult granddaughter. When Dora asked Natalie, Louise; s granddaughter how she was doing, her granddaughter said Louise was experiencing loneliness and isolation due to her weakened immune system - her isolation also meant she could attend daily mass and was very frustrated at not being able to care for her home. She missed her friends, her travel, her spiritual life. Without the ability to be of service to the people she loved, she felt that her life lacked purpose, and her health and wellbeing were impacted by her diminished sense of worth. Dora could see clearly why none of Louise's hospitalizations could fix that, and she had an idea about who might be able to help. Dora called Louise's clinic and got Natalie a phone consultation with an occupational therapist (OT). Natalie and the OT discussed Louise's situation in detail and came up with the following plan: (1)the person who helped with housekeeping would include Louise in whatever way her energy level could allow, (2) a nun would visit her weekly and bring communion and also call her for a brief phone visit at the same time every day (she thrived on routine), and (3) another volunteer visitor happened to have a counseling background, so he 
could easily recognize her tendency to get stuck in her thoughts of anxiety and help steer their conversations onto more enjoyable subjects.

The result of this simple plan was zero hospitalizations in the following three years. Before this intervention, during each of Louise's 58 hospital admissions, each member of the team had done an excellent job of assessing everything they were supposed to assess and treating everything they were supposed to treat. The problem was not that any members of the team failed to do their jobs; the problem was that before there was an OT on the team, it was no one's job to focus on how improving Louise's daily activities could improve her overall health. The sort of creative problem solving the OT used to help restore Louise's quality of life is a skill that is not exclusive to OTs. It is, however, every OT's specialty; that's what OTs do. Occupational therapists ask questions nobody else is likely to ask, and they are masters at coming up with small solutions that solve big problems.

Our willingness to pause and wonder about whether we have the right players on the team is fundamental to team effectiveness. Particularly in instances in which problems, challenges, and crises persist (as they did in Louise's cases), it's important for teams to take time to wonder together about who may need to be added to the team in order to save them time and save their patients unnecessary suffering, in the long run. Any time we're faced with frequent readmissions or "nonadherence" to treatment, that's a cue to get curious and wonder - what new perspective may be needed?

Following is the practice of listening to and focusing on what a team member is teaching us about what matters most to her and allowing that information to guide our interactions with her.

When you recall the feeling of being part of an amazing team, do you recall members who were particularly gifted at creating an environment for the team to do their best work? Perhaps they emerged as ad hoc leaders. They may have cultivated an energizing team culture in subtle ways perhaps by demonstrating genuine interest in each person. They listened to what each person had to say; they were curious about each team member's thoughts and feelings; and they noticed if someone was quiet or being talked over, and steered team dialogue toward more balanced participation. They may have been a sounding board, helping the team reflect on processes or interactions. They may have demonstrated what it looks like to offer a trustworthy ear, even when team members expressed raw, awkward emotions such as fear, shame, or grief. These are examples of what "following" behaviors can look like in team settings.

We are all more likely to thrive with the support of someone who listens and brings out the best in a team, perhaps seeing potential the team didn't see in itself. Team members follow when they take an active interest in one another's opinions. Diverse opinions emerge when people feel it is safe to speak up and that others care about their perspective.

Relationally adept teams explicitly embrace diverse opinions, encouraging conversational turn-taking, as well as allowing for the silence of those who participate best by listening intently without comment. Team norms reinforce the value of following each member and following the team as a whole. Following was demonstrated by Leah's care team when they listened to her parents' input, embracing them as members of the care team, and adapted treatment plans to reduce suffering for Leah.

Following enabled the team to more quickly learn from one another and to learn as a team.

Holding is the practice of intentionally creating psychological safety within the team by demonstrating respect and caring and by supporting conversational turn-taking. 
Holding can be described as verbal and nonverbal behaviors that communicate unconditional warm regard and nonjudgment toward another. When we talk about team trust and psychological safety, two main types of trust are in play.

The first is role-based trust, which means we assume that the individual within a process has the training, scope of practice, judgment, and skills to perform competently. It means, "I trust that you know your job and that you will do it to the best of your ability."

Role-based trust assumes that people within their roles will act to the limit of their scope of practice and fulfill their responsibilities.

The second is interpersonal trust, which can be defined as having mutual respect and concern for one another. Meaningful interpersonal interactions require interpersonal trust. This kind of trust can be expressed as, "I trust that I can count on you as a person."

Psychological safety-the sense that one will not be belittled, attacked, or ignored-is the bedrock of interpersonal trust. When interpersonal trust is high, people feel that it is safe to express vulnerability through such actions as asking for and accepting help or raising concerns on behalf of the patient and family.

Notably, interpersonal trust has a stronger positive correlation with team performance than rolebased trust (Webber, 2008). Therefore, integrating behaviors that communicate nonjudgmental holding are critical to health care team performance. Within a holding environment, team members learn, discover insights, and gracefully recover from mistakes. When errors happen or omissions are made, it can take a terrible toll on everyone. The increase in burnout, addiction, and suicide point to the impact on providers as the "second victims" of medical mistakes (Wu, 2000). There is no question that the patient and family are the primary focus, but when health care professionals make mistakes, they are often traumatized and suffer silently.

The key is for teams to offer a safe space for one another in which to talk about and learn from mistakes. Learning is lost if people feel they will be punished and judged harshly. A team mindset of unconditional warm regard does not mean that everyone on the team likes everyone else or enjoys their company. It means they hold each person with respect, kindness, and the acknowledgment that they are human too. They suffer too. They have insecurities, wounds, and fears just like we do, and they want to feel valued and appreciated just like we do.

Additionally, holding another with unconditional regard doesn't mean we condone recklessness or enable failure to learn.

On the contrary, it means we explicitly socialize teaming behaviors that foster accountability, caring, direct language, displaying vulnerability, inviting participation, and acknowledging our limits.

This talk began with a reflection on how people in the field of aviation learned the importance of psychological safety as a condition for team members to speak up.

Role-based trust, combined with interpersonal trust as a team norm, creates psychological safety. Prior to "crew resource management," a set of training procedures for use in environments in which human error can have devastating effects, cockpit culture resembled health care, with pilots and physicians at the tops of their respective hierarchies.

Lacking interpersonal trust, cockpit crew members feared speaking up and disagreeing with the pilot. Similarly, if interpersonal trust is lacking in a health care team, members hesitate to question physicians and others. Indeed, over the years, we have observed teams so devoid of interpersonal trust that one physician would not question another. 
Analyses of cockpit voice recordings from crashes prior to crew resource management revealed instances of cockpit crewmembers indirectly attempting to give pilots critical but conflicting information. These veiled attempts failed because of the cockpit culture, which was low in interpersonal trust, and fatal crashes ensued.

This risky behavior of indirect communication occurs in health care as well. Medical residents may be working side by side with nurses or other team members who have more years of clinical experience. These team members sometimes "tiptoe," employing indirect, veiled language because of a culture of role hierarchy. Tiptoeing is a sure sign of insufficient interpersonal trust.

A more effective environment for any new clinician is one in which mentoring and coaching across disciplines is the norm.

This kind of culture allows new team members to drop the façade of perfection and invulnerability in exchange for psychological safety and shared learning within the team. Health care organizations do best when, as in aviation, they embrace both the technical and the human dimensions of improving processes. This all has an effect on patients and families as well.

In health care, when both role-based trust and interpersonal trust are high, the team fulfills a third trust-the trust that patients and families place in the team.

The trust they have in us is rarely articulated, and it may not be based on anything beyond the logistics of the current situation. Consider this analogy: If you were falling from a high cliff, and the group of people below included firefighters, you'd trust the firefighters to figure out how to catch you or at least to give you the softest landing possible.

In health care, people are sometimes just that vulnerable; when they're not literally falling into our arms, they're still trusting us to catch them, no matter what happens, or at least to break their fall.
This is why healthy teaming is so important. If one member of a team is just showing up and doing tasks but isn't really part of the team, that person is putting a hole in the team, through which the patient and family may eventually fall. Disengaged team members destroy holding because you can catch only so much with a broken net.

The noble cause of health care provides all of us with a responsibility to honor the trust extended to us by patients, their families, and the communities we serve. It is a hope-filled trust. They trust us to hold their wellbeing in the center of all we do. Our job-our privilege-is to do everything in our power to fulfill the inherent trust extended to us by every person who comes into our care. That is our sacred trust.

\section{Bibliografía}

1. Boeing. (2014). Statistical summary of commercial jet airplane accidents: Worldwide operations 1959-2014. Retrieved from http://www.boeing.com/resources/boeingdot com/company/about_bca/pdf/statsum.pdf

2. Chesley B. "Sully" Sullenberger: Making safety a core business function [Interview]. (2013, October). Healthcare Financial Management, 67, 50-54.

3. Classen, D. C., Resar, R., Griffin, F., Federico, F., Frankel, T., Kimmel, N., . . James, C. (2011). Global "trigger tool" shows that adverse events in hospitals may be ten times greater than previously measured. Health Affairs, 30(4), 581-589. doi: $10.1377 /$ hlthaff.2011.0190

4. Duhigg, C. (2016, February 25). What Google learned from its quest to build the perfect team. The New York Times Magazine. Retrieved from http: //www.nytimes.com/2016/02/28/magazine/ what-google-learned-from-its-questtobuild-the-perfect-team.html 
5. Edmundson, A. (2012). Teaming: How organizations learn, innovate, and compete in

6. Goleman, D. (1998). Working with emotional intelligence. New York: Bantam.

7. Goleman, D., \& Boyatzis, R. (2008, September). Social intelligence and the biology of leadership. Harvard Business Review. Retrieved from https: //hbr.org/2008/09/socialintelligence-and-the biology-of-leadership

8. Helmreich, R., Merrit, A., \& Wilhelm, J. (1999). The evolution of crew resource management training in commercial aviation. International Journal of Aviation Psychology, 9(1), 19-32. doi: $10.1207 /$ s15327108ijap0901_2

9. Kita, J. (2010, October). Doctors confess their fatal mistakes. Reader's Digest.Retrieved from http://www.rd.com/health/conditions/doctor s-confess-their-fatal-mistakes /

10. Kohn, L. T., Corrigan, J. M., \& Donaldson, M. S. (Eds.) (2000). To err is human: Building a safer health system (IOM Report). Retrieved from https: //www.nap.edu/catalog/9728/to-erris-human-building-a-safer-health-system

11. Koloroutis, M. (2017). See me as a person therapeutic practices: Core competencies applied to teams In Koloroutis, M., \& Abelson, D. (Eds.), Advancing relationship-based cultures (pp.279-281). Minneapolis, MN: Creative Health Care Management.

12. Koloroutis, M., \& Trout, M. (2012). See me as a person: Creating therapeutic relationships with patients and their families. Minneapolis, MN: Creative Health Care Management.

13. Landrigan, C. P., Parry, G. J., Bones, C. B., Hackbarth, A. D., Goldman, D. A., \& Sharek, P. J. (2010). Temporal trends in rates of patient harm resulting from medical care. New England Journal of Medicine, 363, 2124-2134. doi: $10.1056 /$ NEJMsa 1004404

14. Lieberman, M. D. (2013). Social: Why our brains are wired to connect. New York: Crown. the knowledge economy. San Francisco: Jossey-Bass.

15. Makary, M. A., \& Daniel, M. (2016). Medical error-the third leading cause of death in the US. British Medical Journal, 353(i2139). doi: $10.1136 /$ bmj.i2139

16. Moorthy, K., Munz, Y., Adams, S., Pandey, V., \& Darzi, A. (2005). A human factors analysis of technical and team skills among surgical trainees during procedural simulations in a simulated operating theatre. Annals of Surgery, 242(5), 631-639. doi: 10.1097/01.sla.0000186298.79308.a8

17. Shanafelt, T. D. (2009). Enhancing meaning in work: A prescription for preventing physician burnout and promoting patient-centered care. Journal of the American Medical Association, 302(12), 1338-1340.

doi:

$10.1001 /$ jama.2009.1385

18. Siegel, D. (2007). The mindful brain: Reflection and attunement in the cultivation of wellbeing. New York: W.W. Norton.

19. Woolley, A. W., Chabris, C. F., Pentland, A., Hashmi, N., \& Malone, T. W. (2010). Evidence for a collective intelligence factor in the performance of human groups. Science, 330(6004), 686-688. doi: $0.1126 /$ science.1193147

20. Wu, A. W. (2000). Medical error: the second victim. British Medical Journal, 320, 726. doi: $10.1136 /$ bmj.320.7237.726

21. Yule, S., Flin, R., Paterson-Brown, S., Maran, N., \& Rowley, D. (2006). Development of a rating system for surgeons' non-technical skills. Medical Education, 40(11), 1098-104. doi: $10.1111 / j .1365-929.2006 .02610 . x$ 